\title{
Skin disorders in diabetes mellitus: an epidemiology and physiopathology review
}

\author{
Geisa Maria Campos de Macedo ${ }^{1 *}$, Samanta Nunes ${ }^{2}$ and Tania Barreto ${ }^{3}$
}

\begin{abstract}
Skin disorders, usually neglected and frequently underdiagnosed among diabetic patients, are common complications and encounter a broad spectrum of disorders in both type 1 and type 2 diabetes mellitus (DM) - e.g. cutaneous infection, dry skin, pruritus. Skin disorders are highly associated with increased risk of important outcomes, such as skin lesions, ulcerations and diabetic foot, which can lead to major complications and revolve around multifactorial factors besides hyperglycemia and advanced glycation end products. Although diabetic's skin disorders are consistent in the literature, there is limited data regarding early-stage skin disorders in DM patients. Disease control, early-stage treatment (e.g. skin hydration, orthotic devices) and awareness can reduce morbidity of DM patients. Thus, better understanding of the burden of skin disorders in DM patients may raise awareness on prevention and management. Therefore, the aim of this study is to perform a literature review to evaluate the main clinical characteristics and complications of skin disorders in diabetic's patients. Additionally, physiopathology early-stage skin disorders and dermocosmetic management were also reviewed.
\end{abstract}

Keywords: Diabetes mellitus, Skin disorders, Non-pharmacological treatment

\section{Background}

Skin disorders, usually neglected and frequently underdiagnosed among diabetic patients, are common complications and encounter a broad spectrum of disorders in both type 1 and type 2 diabetes mellitus (DM)-e.g. cutaneous infection, dry skin, pruritus-that can lead to major complications and are highly associated with hyperglycemia and advanced glycation end products (AGEs) [1].

Although diabetic's skin disorders are consistent in the literature, there is limited data regarding early-stage skin disorders in DM patients, especially focusing on noninjured skin [2]. Better understanding of the burden of skin disorders in diabetes patients may raise awareness on prevention and management. Therefore, the aim of this study is to perform a literature review to evaluate the main clinical characteristics and complications of skin disorders in diabetic's patients. Additionally, management of skin disorders was also reviewed.

\footnotetext{
*Correspondence: gmcm2005@hotmail.com

${ }^{1}$ Endocrine and Diabetes Department, Agamenon Magalhães Hospital,

Estrada do Arraial, 2723, Casa Amarela, Recife, PE 52070-230, Brazil

Full list of author information is available at the end of the article
}

\section{Skin disorders in diabetes and epidemiology}

Diabetes mellitus (DM) represents a high prevalent disease with high morbidity and mortality. In 2014, there were 387 million diagnosed cases of diabetes and 4.9 million deaths worldwide. Additionally, about $77 \%$ of people with diabetes live in less developed regions [3]. Although prevalence of diabetes morbidity is high, specific data on complications related to skin disorders are limited. Several epidemiological studies evaluating occurrence of skin disorders on type 1 and type $2 \mathrm{DM}$ were performed worldwide, with pattern of skin disorders varying according to DM type and region where the study was conducted.

Overall prevalence of skin disorder in both type 1 and 2 DM varied from 51.1 to $97 \%$ in different regions worldwide. The high prevalence of dermatological disorder among DM patients described in literature endorses the clinical importance and high impact of this complication.

Although study design and eligibility criteria of the included patients varied slightly among reported studies, most frequent disorder reported in diabetic patients, regardless of DM type, was infection-occurring in at least $20.6 \%$ of diagnosed patients. Moreover, fungal 
infections were more prevalent than bacterial or viral infections [4-8], and interdigital spaces, genitalia and skin folds were the most frequent site of infection [4].

In a single center epidemiologic study conducted in Iran, infection was also the most common lesion reported by patients-in this study, the most common noninfectious manifestation was pruritus [9]. Similarly, Sasmaz et al. showed that most common skin conditions in DM patients are infections (31.7\%), non-candidal intertrigo (20.5\%), eczemas (15.2\%), psoriasis (11.2\%), diabetic dermopathy (11.2 \%), and prurigo (9.9\%) [5].

A study conducted in Brazil evaluated 403 patients with type $1(\mathrm{n}=125)$ and type $2(\mathrm{n}=278) \mathrm{DM}$ assisted in the outpatient clinic from Ribeirão Preto Hospital in 2000. The study demonstrated that $81 \%$ of patients had at least one dermatologic lesion, with a mean of 3.7 lesions per patient, being dermatophytosis the most common lesion. Of all dermatophytosis, $42.6 \%$ were onychomycoses $(n=172)$ and $29.2 \%$ were tinea pedis $(n=118)$. Skin lesions occurring in more than $10 \%$ of the patients were actinic degeneration (62\%), skin xerosis (20.8\%), benign skin tumor (23.5\%), candidiasis (12.9\%) and scar $(12.6 \%)[6]$.

Another study in Brazil, also conducted in the outpatient clinic from Ribeirão Preto Hospital from 2003 to 2004, evaluated $500 \mathrm{DM}$ patients. The study demonstrated that $97 \%$ of all patients had at least one skin lesion-the highest skin disorder rate in this reviewbeing tinea pedis (35\%), candidiasis of the skin/nail $(26 \%)$, pigmentation disorders (22\%), xerosis (22\%) and tinea unguium $(22 \%)$ the most commonly reported dermatological diagnoses among DM patients [10].

A smaller study in Brazil conducted in Canoas with 55 patients also demonstrated a high prevalence of skin disorders among DM patients (89.1\%), comprising of yellow nails $(52.7 \%)$, candidiasis $(52.7 \%)$, dermatophytosis (50.9 \%), nail dystrophy (45.5\%) and Staphylococcus infections (38.2\%) [11].

Galdeano et al. evaluated 125 patients with type 1 and $2 \mathrm{DM}$ in a single center in Argentina. The study showed a high prevalence of skin disorders: $90.4 \%$. Skin disorders occurring in more than $10 \%$ of the patients included xeroderma (69\%), dermatophytosis (52\%), onychomycosis. (49\%), tineapedis (39\%), peripheral hypotrichia (39\%), diabetic dermopathy (35\%) skin thickening syndrome $(25 \%)$, diabetic foot (24\%), candidiasis (17\%), fibroids pendulums (11\%), intertrigo (10\%), and inner eyebrow separation (10 \%) [12].

In Egypt, Sanad et al. evaluated 100 patients diagnosed with type $1(n=23)$ and type $2(n=77) D M$, with at least one skin lesion, in a single center cohort study. The mean time of diagnosis was $10.57 \pm 7.63$ years. In this study, the most common skin disorders were cutaneous infections
(40\%), followed by pruritus (11\%), local reactions at the site of insulin injection (8\%), vitiligo (8\%), diabetic dermopathy (7\%), periungual telangiectasia (6\%), and xanthelasma (5\%). Xerosis was reported in only $3 \%$ of patients. Cutaneous infections included fungal (22\%), bacterial (16\%), and viral (2\%) infections. Tinea pedis was the most common fungal infection (12\%), whereas boils were the most common bacterial infection (5\%). Among viral infections, one patient had herpes simplex and another had herpes zoster [7].

Differences between patterns of lesions remain unclear among types of diabetes. A total of five studies evaluated skin disorders in both types 1 and 2DM. Chattergee et al. showed higher prevalence of skin disorder in type $2 \mathrm{DM}$ (75.6 vs $41 \%$ ). In this same study, the most common skin disorders on type $1 \mathrm{DM}$ were diabetic xerosis, infections and diabetic hand. Differently, most frequent disorders presented in patients with type $2 \mathrm{DM}$ were infections, xerosis, hair loss below the knees and diabetic dermopathy [13].

One case-control study evaluating type $1 \mathrm{DM}$ in young patients showed that the most prevalent skin disorder was xerosis, occurring in $22.2 \%$ of patients compared to $3 \%$ in the control group $(\mathrm{p}<0.01)$ [14]. Another study evaluating type $1 \mathrm{DM}$ in young patients $(\mathrm{n}=500)$, conducted in South Asia, demonstrated that the most common disorders related to the disease were limited joint complication (16.8\%), xerosis (15.8\%) and sclerodermalike skin changes $(10 \%)$. The author also reported complications related to disease treatment, which included lipohypertrophy (41\%), postinflammatory hyperpigmentation (3\%) and lipoatrophy (0.6\%) [15].

Additionally, Farshchian et al. also reported differences on patterns of infection according to the types of diabetes. In the type $1 \mathrm{DM}$, the most frequent cutaneous infections were viral warts, while pyodermas were the most frequent cutaneous infections in type $2 \mathrm{DM}$ patients [9]. Although prevalence of skin disorders appears to be higher in type $2 \mathrm{DM}$, these disorders should be monitored in early stage regardless of type of diabetes and manifestation.

Overall, cutaneous infection and xerosis showed to be highly prevalent and important skin disorders in several studies, regardless DM type. Among cutaneous infections, fungal etiology appears to be the most common and those with bacterial origin are the less frequent [48]. Other outcomes such as xeroderma, reactions related to the treatment, eczema, pruritus, xanthelasma, and diabetic dermopathy were also reported and should be monitored too.

Although prior studies showed increased risk of infection in DM patients [16], little evidence is found in the literature to support increased risk for cutaneous infectious diseases [9]. In general, skin disorders are highly 
associated to poorly controlled DM patients. A good glycemic control may reduce the incidence and severity of cutaneous disorders with or without known pathogenesis [17]. Nonspecific skin disorders that occur in DM patients can increase the likelihood of exposure to infectious organisms and contact with allergens, resulting in chronic and recurrent infections and eczemas, respectively [17]. However, further studies are required, since all available data are still not concordant. Additionally, Farshician et al. did not find a significant relationship between the diabetic disease control and the prevalence of cutaneous infection [9]. Moreover, most cross-sectional studies assessed in this review do not allow causal explanations. Thus, further investigation is required to better understand the risk of cutaneous infection.

Xerosis was reported in several studies and rates showed high heterogeneity. Goyal et al. showed a high prevalence of xerosis (44\%) in a single center observational study mainly related to weather and dry climatic conditions [8]. According to Pavlovic, skin dryness is one of the earliest and most common manifestations of type $1 \mathrm{DM}$ [14]. Clinical observations are supported by a reduced hydration state of the stratum corneum and decreased sebaceous gland activity in DM patients, without any impairment of the stratum corneum barrier function. Even in the absence of clinically apparent xerosis, patients with diabetes have an impaired desquamation process. Furthermore, occurrence of xerosis may be affected not only by the type of diabetes but also to regional changes in climate and humidity [7].

\section{Major pathways on skin disorders in DM}

Skin disorders in DM patients are highly correlated with glycemic control. As an example, Foos et al. conducted a study with 403 DM patients in Brazil and evaluated their skin disorders and glycaemia control. Thus, the study demonstrated that $94 \%$ of patients with inadequate glycaemia control had some skin disorder; on the other hand, only $60 \%$ of DM patients with adequate glycaemia control had some skin disorder [6].

DM affects the skin through several mechanisms, being hyperglycemia per se and AGEs the most well-described. Reaching pathological high levels of glycaemia strongly affects skin homeostasis by inhibiting keratinocyte proliferation and migration, protein biosynthesis, inducing endothelial cell apoptosis, decreasing nitric oxide synthesis and impairing phagocytosis and chemotaxis from several cells $[18,19]$. Besides hyperglycemia induce direct damage, high glucose levels also induce AGE formation. AGEs are formed from glycation of proteins, lipids and nucleic acids $[18,19]$ that act in several pathways, inducing reactive oxygen species (ROS) formation, impairing ROS clearance, as well as intra and extracellular proteins function, and inducing pro inflammatory cytokine through nuclear factor $\kappa \beta$ (NF-k $\beta$ ) pathway [20].

Indeed, AGE biochemical interactions are one of the major pathways involved in DM complications, including skin disorders [21]. AGE alters collagen properties, decreasing flexibility and solubility and increasing its rigidity [22]. Also, AGEs participate in the development of fibrosis in DM [23], in skin aging [20] and even in diabetes-related immunosuppression [24]. Diabetes-related immunosuppression affects skin wounding, mainly by leukocyte impaired function and misbalanced/malfunction of growth factors [25].

In addition to the previously mentioned pathways, high glucose levels also impair the normal functioning of keratinocytes in vitro, decreasing its proliferation and differentiation [26, 27]. Moreover, keratinocytes studies are more commonly conducted in animal models, with scarce data on diabetic human skin [2]. Regarding epidermal thickness alterations, Bertheim et al. demonstrated that diabetic patients with severe joint mobility on the hands had an increased epidermal thickness, with abnormal hyaluronan distribution on skin layers [28], while Zakharov et al. demonstrated that well-controlled patients with type $1 \mathrm{DM}$ did not presented alteration on the epidermal thickness [29]. This data reinforces that skin disorders in DM patients are strongly related to glycaemia control.

Table 1 summary of studies reporting skin disorders prevalence in DM 1 and DM 2 patients, with a subjects description (number of subjects in the study, type of DM evaluated, country/region where the study was conducted, subjects mean age), prevalence of skin condition and the most common skin condition in each study.

A summary of skin evaluation studies performed in humans is described in Table 2 [28-33].

Cutaneous manifestations in DM patients are mainly classified into four categories in order to support management of the outcomes, especially due to innumerous potential causes:

1. Skin lesions with strong to weak association with diabetes (necrobiosis lipoidica, diabetic dermopathy, diabetic bullae, yellow skin, eruptive xanthomas, perforating disorders, acanthosis nigricans, oral leucoplakia, lichen planus).

2. Infections (bacterial, fungal).

3. Cutaneous manifestations of diabetic complications (microangiopathy, macroangiopathy, neuropathy).

4. Skin reactions to diabetic treatment (sulphonylureas or insulin) [4].

Considering cutaneous manifestations on DM, some skin conditions are more likely to affect type 1 or $2 \mathrm{DM}$ 
Table 1 Summary of studies reporting skin disorders prevalence in DM 1 and DM 2 patients, with a subjects description (number of subjects in the study, type of DM evaluated, country/region where the study was conducted, subjects mean age), prevalence of skin condition and the most common skin condition in each study

\begin{tabular}{|c|c|c|c|c|c|c|}
\hline Author & Sample size & DM type & Country/region & Age (years) & Overall prevalence (\%) & $\begin{array}{l}\text { Overall most frequent } \\
\text { skin disorder among all } \\
\text { disorders (\%) }\end{array}$ \\
\hline Sasmaz et al. [5] & 151 & Type 2 & India & $54 \pm 17$ & 85.4 & $\begin{array}{l}\text { Cutaneous infection } \\
(20.6 \%)\end{array}$ \\
\hline Chatterjee, et al. [13] & 680 & Types 1 and 2 & India & $46.3 \pm 6.7$ & 73.9 & $\begin{array}{l}\text { Cutaneous infection } \\
(40.9 \%)\end{array}$ \\
\hline Farshchian et al. [9] & 155 & Types 1 and 2 & Iran & $\begin{array}{l}21.8 \pm 4.9 \text { and } \\
57.2 \pm 9.7, \text { type } 1 \\
\text { and } 2, \text { respectively }\end{array}$ & 71 & Cutaneous infection \\
\hline Foss et al. [6] & 403 & Types 1 and 2 & Brazil & $\begin{array}{l}19.9 \pm 2.3 \text { and } \\
63.1 \pm 3.4 \text { type } 1 \\
\text { and } 2 \text {, respectively }\end{array}$ & 81 & $\begin{array}{l}\text { Cutaneous infection } \\
(82.6 \%)\end{array}$ \\
\hline Wambier et al. [10] & 500 & Types 1 and 2 & Brazil & $45.5 \pm 20$ & 97 & $\begin{array}{l}\text { Cutaneous infection } \\
\text { (i.e.Tinea pedis) (35\%) }\end{array}$ \\
\hline da Silva et al. [11] & 55 & Type 2 & Brazil & $56.3 \pm 13.4$ & 89.1 & $\begin{array}{l}\text { Yellow nails }(52.7 \%) \text { and } \\
\text { candidiasis }(52.7 \%)\end{array}$ \\
\hline Galdeano et al. [12] & 125 & Types 1 and 2 & Argentina & $58.9 \pm 15.43$ & 90.4 & Xeroderma (69 \%) \\
\hline Pavlovic et al. [14] & 212 & Type 1 & Servia & $12.5 \pm 3.7$ & 68 & Xerosis (22.2\%) \\
\hline Romano et al. [4] & 457 & Types 1 and 2 & Italy & $61.5 \pm 11.3$ & 60 & Cutaneous infection \\
\hline Sanad et al. [7] & 100 & Types 1 and 2 & Egypt & $51.42 \pm 14.66$ & - & $\begin{array}{l}\text { Cutaneous infection } \\
(40 \%)\end{array}$ \\
\hline Sawatkar et a [15]! & 500 & Type 1 & South Asia & $16.9 \pm 6.9$ & 67.8 & $\begin{array}{l}\text { Limited joint mobility } \\
\quad(16.8 \%)\end{array}$ \\
\hline Goyal et al. [8] & 100 & Types 1 and 2 & India & $57.44 \pm 10.37$ & - & Xerosis (44 \%) \\
\hline Ragunatha et al. [17] & 500 & Types 1 and 2 & India & $55.24 \pm 11.24$ & 51.1 & Cutaneous infection \\
\hline
\end{tabular}

Table 2 Summary of findings on skin alterations in DM patients

\begin{tabular}{lll}
\hline Parameter & Effect in DM patients & Reference \\
\hline Hydration & Decreased & Sakai et al. [30] \\
& No alteration & Seirafi et al. [31] \\
Trans-epidermal loss & Not altered & Sakai et al. [30] \\
& & Seirafi et al. [31] \\
Filaggrin & Alteration & Thyssen et al. [32] \\
Other possible signs of barrier defect & Increased inflammatory infiltration & Tellechea et al. [33] \\
Epidermal thickness & No alteration & Zakharov et al. [29] \\
& Thicker epidermis & Bertheim et al. [28]
\end{tabular}

Adapted from Quondamatteo [2]

disproportionally. Although with high inter-study variability, skin manifestations demonstrating association with DM type are described in Table 3 [34].

\section{DM skin disorders progression and potential outcomes}

An important variability on severity and potential outcomes is observed among skin disorders in DM. Early-stage skin disorders in DM, such as xerosis, callus and fissures, are usually neglected and frequently underdiagnosed [1]. Lack of diagnosis and treatment on early-stage skin disorders can lead to clinical worsening, and progression to foot neuropathy, ulcers and even amputation [35]. DM-induced neuropathy can reach sensory, motor and autonomic pathways, leading to different dermatologic conditions (Fig. 1).

- Sensory neuropathy: insensibility and decreased temperature sensation, affecting the sensibility on lesions $[36,37]$. 
Table 3 Most frequent skin disorders among type 1 and type 2 DM

\begin{tabular}{ll}
\hline Type 1 diabetes mellitus & Type 2 diabetes mellitus \\
\hline Necrobiosis lipoidica diabeticorum & Generalized granuloma annulare \\
Diabetic bullae & Scleredema diabeticorum \\
Vitiligo vulgaris & Diabetic dermopathy \\
Periungual telangiaecstasia & Acathosis nigricans \\
- & Acrochordons \\
- & Psoriasis
\end{tabular}

Adapted from Murphy-Chutorian et al. [32]

- Motor neuropathy: causes toe and gait deformity, leading to foot deformity and increased plantar pressure $[38,39]$.

- Autonomic neuropathy: leads to anhidrosis and vasodilation, causing dry skin, skin tears and fissures [40], also losing viscoelasticity [41].

All the neuropathies, alone or simultaneously, can lead to neuropathic foot ulcer, the most severe cutaneous lesion, in consequence of the poor healing potential of DM skin [42] that frequently become infected, thus leading to amputation $[43,44]$.

Complications prevention by treating chronic hyperglycemia and early-stage symptoms (e.g. skin hydration, orthotic devices, patient education) is highly acclaimed by medical society, once the diabetic foot brings severe economic, personal, social, and medical impact $[35,45]$. Furthermore, xerosis, callus and foot deformity are the early-stage complications target to avoid the development of diabetic foot. Besides, a continuous patient education is also required to ensure that patients take proper care of the skin and foot.

Although several clinical outcomes related to DM, many cellular impairments are also related to hyperglycemia and hyperinsulinemia. As an example, keratinocytes, which is the predominant cell type in the epidermis, are downregulated in hyperglycemia conditions, with impairment on its proliferation [26]. In addition, a study performed in animal model demonstrated an imbalance on stratum corneum composition (lower triglycerides and higher ceramides, cholesterol and fatty acids levels), when compared to control. Furthermore, another study showed an increased number of corneocyte layers in the stratum corneum and decreased basal cell proliferation and epidermal DNA content-important in epidermal differentiation-suggesting slower stratum corneum and epidermal turnover [46]. Moreover, larger corneocyte surface area is observed in DM patients, when compared to control [47].

The dermis also suffers morphological and biochemical alteration in DM patients due to the synthesis and/

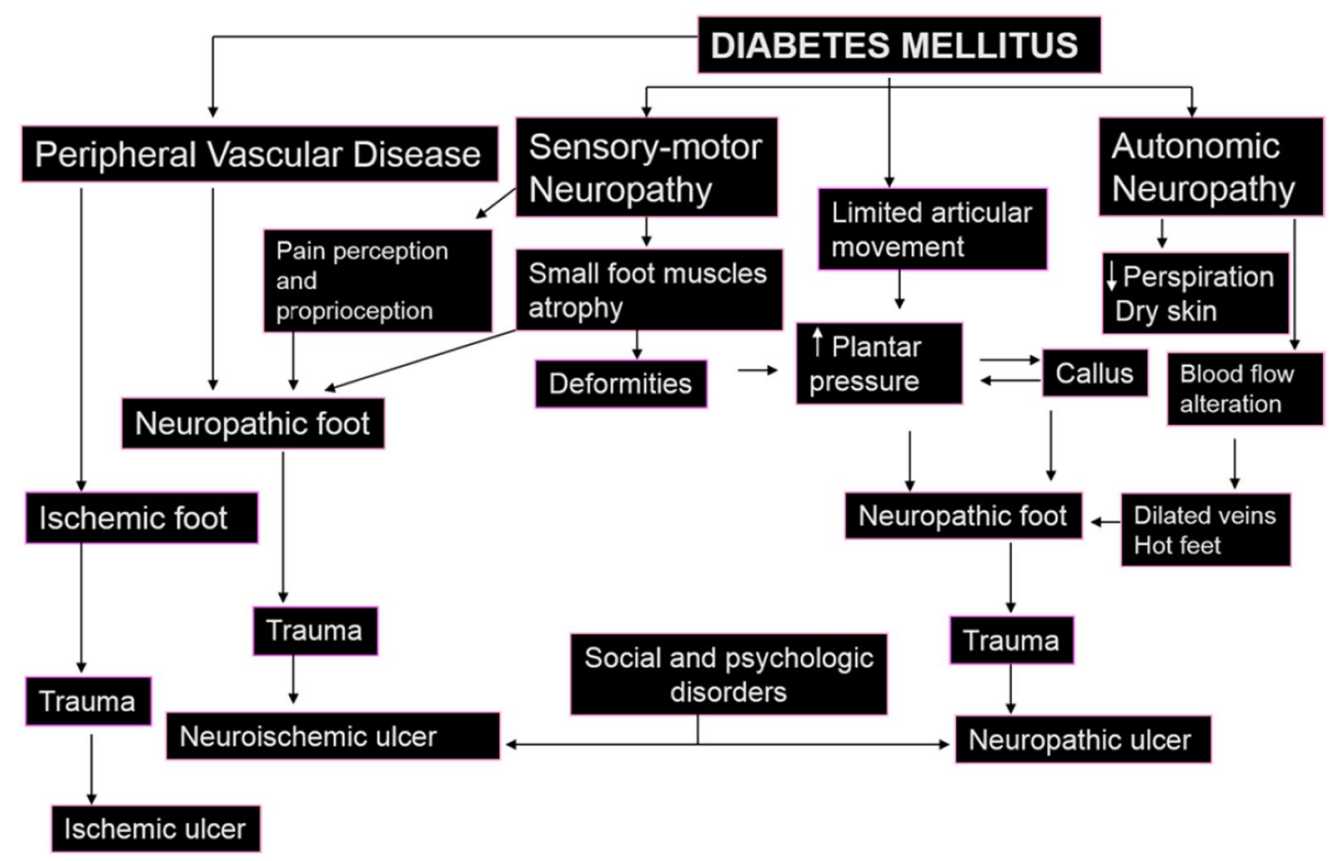

Adapted from. Boulton, 2000

Fig. 1 Neuropathic foot ulcer pathophysiology. Neuropathic foot ulcer physiopathology pathways, with autonomic, motor and sensory neuropathies leading to foot neuropathy. Adapted from Boulton [37] 
or degradation of intracellular matrix and microarchitectural arrangement. Moczar et al. [48] demonstrated that skin biopsies of DM patients had ultrastructural modifications on fibroblast, collagen and elastic fibers in the dermis, with fragmented or absent elastic fibers under the epithelial basal laminae. Additionally, DM patients' dermis presented collagenase and elastase alterations, endorsing the important matrix macromolecules alterations on DM patient's dermis

As a result of all those changes, lower plasticity of the epidermis is seen in DM patients when compared to controls [49], without any alteration in transepidermal water loss (TEWL) [30, 31]. Furthermore, skin surface lipids appeared to be reduced in DM patients [30,31]; also, another study demonstrated decreased skin elasticity in the forearm and forehead. Some of the functional properties of the stratum corneum in DM patients vary according to acute uncontrolled glycaemia (fasting plasma glucose $>110 \mathrm{mg} / \mathrm{dL}$ ) and disease control (HbA1c > $5.8 \%)$. In DM patients with fasting plasma glucose higher than $110 \mathrm{mg} / \mathrm{dL}$, skin surface hydration was lower than in DM patients with fasting plasma glucose lower than $110 \mathrm{mg} / \mathrm{dL}$, with no alteration on TEWL. On the other hand, patients with HbA1c levels higher than $5.8 \%$ have slightly lower TEWL on forearm, with no alteration on skin surface hydration, when compared to patients with HbA1c < $5.8 \%$ [30].

In conclusion, dermocosmetic strategy is an option to treat the biophysical alterations on DM skin, with efficacy on improving skin hydration, decreasing xerosis and scaling among other factors [50].

\section{Skin hydration: avoiding the progression}

Dermocosmetic management through skin hydration and control of xerosis and callus symptoms are essential to avoid progression of skin lesions on DM patients [51]. Regarding dermocosmetic approach, the most commonly used active ingredient is urea. In 2003, Schölermann et al. published the results of two studies with $10 \%$ urea cream in dry skin treatment. In the first study, 603 patients with dry or extremely dry skin, of which 179 were DM patients, were treated with $10 \%$ urea cream for 14 days, presenting a decrease on dryness, callosities and scaling compared to baseline. In the second study, 30 patients with diabetes and/or xerosis were treated in one foot (the other foot was used as control) with $10 \%$ urea cream for 10 days, resulting in decreased callosities, dryness and scaling [52].

Federici et al. conducted a randomized controlled clinical trial with 40 type $2 \mathrm{DM}$ patients who were allocated to receive urea $5 \%$, arginine and carnosine versus a glycerol-based emollient for 28 days. Patients treated with urea $5 \%$, arginine and carnosine presented an $89 \%$ reduction on dryness according to DASI scale when compared to control emollient [53]. Another study conducted with 54 type 1 and 2 DM patients treated with $10 \%$ glycerin, $5 \%$ urea, $1 \%$ lactic acid (moisturizing agents) and $8 \%$ paraffin (occlusive agent) in an emulsion base versus placebo (emulsion base with none of the active ingredients) for 4 weeks also demonstrated a decrease of dryness and fissures and increased skin hydration on activetreated group [54].

Similar studies were performed with $10 \%$ urea and $4 \%$ lactic acid [55]; $10 \%$ urea, Oenothera biennis oil, Centella asiatica extract, $\alpha$-hydroxy acid, allantoin, and panthenol formulation [56]; $5 \%$ urea with $0.2 \%$ hydroxyethylpiperazine ethane sulfonic acid [57]. Polaskova et al. performed a study comparing the 6 urea-containing different formulations for diabetic foot, evaluating TEWL, and demonstrated that urea $6 \%$ formulations maintained or restored adequate barrier function, while urea $4 \%$ formulations presented longer action period [58].

Recently, Nunes et al. published a study performed in 87 Brazilian DM patients evaluating efficacy and safety of cream $(n=43)$ or lotion $(n=44)$ Hidrastar formulations, containing urea, amino acids, linoleic acid, linolenic acid and SH-oligopeptide-2. After 28 days of application twice a day in both feet, $100 \%$ of the patients using Hidrastar cream formulation reported increase in skin hydration, softness, improved texture and overall appearance. In the group using Hidrastar lotion formulation, $79.5 \%$ of patients reported increased hydration, $81.8 \%$ increase in softness, $81.8 \%$ improvement in texture and $86.4 \%$ improvement in the overall appearance of the skin of the feet [59].

\section{Conclusion}

In conclusion, our review confirmed high prevalence of skin disorder in DM patients, showing that careful dermatological examination and outpatient follow-up of DM patients is required to provide them adequate skin management, thus reducing morbidity and complications related to skin. Additionally, in early-stage disorders, such as xerosis and callus, detection and management appeared to be important in reducing complications related to DM. This review summarizes the main articles in skin disorders and diabetes, with some limitations as the absence of statistical summary, from a meta-analysis. Further observational studies are required to clarify differences between types of diabetes and association between disease and risk of occurrence.

\section{Abbreviations}

AGE: advanced glycation end-products; DASI: dryness area severity index; DM: diabetes mellitus; DM1: diabetes mellitus type 1; DM2: diabetes mellitus type 2; NF-k $\beta$ : nuclear factor $\mathrm{k} \beta$; ROS: reactive oxygen species; TEWL: transepidermal water loss. 


\section{Authors' contributions}

GMCM, SN and TB have conducted the literature review and wrote the manuscript. All authors read and approved the final manuscript.

\section{Author details}

${ }^{1}$ Endocrine and Diabetes Department, Agamenon Magalhães Hospital, Estrada do Arraial, 2723, Casa Amarela, Recife, PE 52070-230, Brazil. ${ }^{2}$ Brazilian Society of Dermatology São Paulo, São Paulo 05423 010, Brazil. ${ }^{3}$ Diabetes Division, Sanofi, São Paulo, São Paulo 05693-000, Brazil.

\section{Acknowledgements}

The authors would like to acknowledge Guilherme S. Julian, M.Sc. and Eimy Minowa, B.Pharm., who provided support with literature review and manuscript preparation on behalf of Evidências-Kantar Health, with funding from Sanofi.

\section{Competing interests}

GMCM and SN are members of the advisory board of the company Sanofi; TB is employed by Sanofi. The authors declare that they have no competing interests.

Received: 15 January 2016 Accepted: 9 August 2016

Published online: 30 August 2016

\section{References}

1. Wang YR, Margolis D. The prevalence of diagnosed cutaneous manifestations during ambulatory diabetes visits in the United States, 1998-2002. Dermatology. 2006;212:229-34.

2. Quondamatteo F. Skin and diabetes mellitus: what do we know? Cell Tissue Res. 2014;355:1-21

3. Federation ID. IDF diabetes atlas. 6th ed. Brussels: International Diabetes Federation; 2013.

4. Romano G, Moretti G, Di Benedetto A, Giofre C, Di Cesare E, Russo G, et al. Skin lesions in diabetes mellitus: prevalence and clinical correlations. Diabetes Res Clin Pract. 1998:39:101-6.

5. Sasmaz S, Buyukbese M, Cetinkaya A, Celik M, Arican O. The prevalence of skin disorders in type-2 diabetic patients. Int J Dermatol. 2004;3(1). http:// www.ispub.com/ostia/index.php?xmlFilePath=journals/ijd/vol3n1/diabetes.xml.

6. Foss NT, Polon DP, Takada MH, Foss-Freitas MC, Foss MC. Dermatoses em pacientes com diabetes mellitus. Revista de Saúde Pública. 2005;39:677-82.

7. Sanad EM, EIFangary MM, Sorour NE, EINemisy NM. Skin manifestations in Egyptian diabetic patients: a case series study. Egypt J Dermatol Venereol. 2013;33:56-62.

8. Goyal A, Raina S, Kaushal SS, Mahajan V, Sharma NL. Pattern of cutaneous manifestations in diabetes mellitus. Indian J Dermatol. 2010;55:39-41.

9. Farshchian M, Fereydoonnejad M, Yazdanfar A, Kimyai-Asadi A. Cutaneous manifestations of diabetes mellitus: a case series. Cutis. 2010;86:31-5.

10. Wambier CG, Takada MH, Foss-Freitas MC, Frade MAC, Foss MC, Foss NT. Effects of metabolic control on cutaneous findings in diabetes mellitus. Revista Brasileira de Medicina Interna. 2014;1:11-9.

11. da Silva MCA, Mazzotti NG, Weber MB. Manifestações cutâneas em pacientes com diabete melito tipo 2 em posto de saúde. Revista da Associação Médica do Rio Grande do Sul. 2007:51:95-9.

12. Galdeano F, Zaccaria S, Parra V, Giannini ME, Salomón S. Cutaneous manifestations of diabetes mellitus: clinical meaning. Dermatología Argent. 2013;16:117-21.

13. Chatterjee N, Chattopadhyay C, Sengupta N, Das C, Sarma N, Pal SK. An observational study of cutaneous manifestations in diabetes mellitus in a tertiary care hospital of Eastern India. Indian J Endocrinol Metab. 2014;18:217-20.

14. Pavlovic MD, Milenkovic T, Dinic M, Misovic M, Dakovic D, Todorovic S, et al. The prevalence of cutaneous manifestations in young patients with type 1 diabetes. Diabetes Care. 2007;30:1964-7.

15. Sawatkar GU, Kanwar AJ, Dogra S, Bhadada SK, Dayal D. Spectrum of cutaneous manifestations of type 1 diabetes mellitus in 500 South Asian patients. Br J Dermatol. 2014:171:1402-6.
16. Shah BR, Hux JE. Quantifying the risk of infectious diseases for people with diabetes. Diabetes Care. 2003;26:510-3.

17. Ragunatha S, Anitha B, Inamadar AC, Palit A, Devarmani SS. Cutaneous disorders in 500 diabetic patients attending diabetic clinic. Indian J Dermatol. 2011;56:160-4.

18. Blakytny R, Jude EB. Altered molecular mechanisms of diabetic foot ulcers. Int J Low Extrem Wounds. 2009:8:95-104.

19. Behm B, Schreml S, Landthaler M, Babilas P. Skin signs in diabetes mellitus J Eur Acad Dermatol Venereol. 2012;26:1203-11.

20. Gkogkolou P, Bohm M. Advanced glycation end products: key players in skin aging? Dermatoendocrinology. 2012:4:259-70.

21. Nicholl ID, Stitt AW, Moore JE, Ritchie AJ, Archer DB, Bucala R. Increased levels of advanced glycation endproducts in the lenses and blood vessels of cigarette smokers. Mol Med. 1998;4:594-601.

22. Avery NC, Bailey AJ. The effects of the Maillard reaction on the physical properties and cell interactions of collagen. Pathol Biol. 2006;54:387-95.

23. Yuen A, Laschinger C, Talior I, Lee W, Chan M, Birek J, et al. Methylglyoxalmodified collagen promotes myofibroblast differentiation. Matrix Biol. 2010;29:537-48.

24. Frykberg RG, Zgonis T, Armstrong DG, Driver VR, Giurini JM, Kravitz SR, Diabetic foot disorders. a clinical practice guideline. J Foot Ankle Surg. 2006:2006(45):S1-66.

25. Greenhalgh DG. Wound healing and diabetes mellitus. Clin Plast Surg. 2003:30:37-45

26. Spravchikov N, Sizyakov G, Gartsbein M, Accili D, Tennenbaum T, Wertheimer E. Glucose effects on skin keratinocytes: implications for diabetes skin complications. Diabetes. 2001:50:1627-35.

27. Chen XF, Lin WD, Lu SL, Xie T, Ge K, Shi YQ, et al. Mechanistic study of endogenous skin lesions in diabetic rats. Exp Dermatol. 2010;19:1088-95.

28. Bertheim U, Engstrom-Laurent A, Hofer PA, Hallgren P, Asplund J, Hellstrom S. Loss of hyaluronan in the basement membrane zone of the skin correlates to the degree of stiff hands in diabetic patients. Acta Derm Venereol. 2002:82:329-34.

29. Zakharov P, Talary MS, Kolm I, Caduff A. Full-field optical coherence tomography for the rapid estimation of epidermal thickness: study of patients with diabetes mellitus type 1. Physiol Meas. 2010;31:193-205.

30. Sakai S, Kikuchi K, Satoh J, Tagami H, Inoue S. Functional properties of the stratum corneum in patients with diabetes mellitus: similarities to senile xerosis. Br J Dermatol. 2005;153:319-23.

31. Seirafi H, Farsinejad K, Firooz A, Davoudi SM, Robati RM, Hoseini MS, et al. Biophysical characteristics of skin in diabetes: a controlled study. J Eur Acad Dermatol Venereol. 2009;23:146-9.

32. Thyssen JP, Linneberg A, Carlsen BC, Johansen JD, Engkilde K, Hansen $T$, et al. A possible association between a dysfunctional skin barrier (filaggrin null-mutation status) and diabetes: a cross-sectional study. BMJ Open. 2011;1:e000062.

33. Tellechea A, Kafanas A, Leal EC, Tecilazich F, Kuchibhotla S, Auster ME, et al. Increased skin inflammation and blood vessel density in human and experimental diabetes. Int J Low Extrem Wounds. 2013:12:4-11.

34. Murphy-Chutorian B, Han G, Cohen SR. Dermatologic manifestations of diabetes mellitus: a review. Endocrinol Metab Clin N Am. 2013:42:869-98.

35. Boulton AJ, Vileikyte L, Ragnarson-Tennvall G, Apelqvist J. The global burden of diabetic foot disease. Lancet. 2005;366:1719-24.

36. Boulton AJ. The diabetic foot: a global view. Diabetes Metab Res Rev. 2000;16(Suppl 1):S2-5.

37. Boulton AJM. The Pathway to ulceration: aetiopathogenesis. The foot in diabetes. USA: Wiley; 2002. p. 19-31.

38. Armstrong DG, Lavery LA, Vela SA, Quebedeaux TL, Fleischli JG. Choosing a practical screening instrument to identify patients at risk for diabetic foot ulceration. Arch Intern Med. 1998;158:289-92.

39. van Schie $\mathrm{CH}$. A review of the biomechanics of the diabetic foot. Int J Low Extrem Wounds. 2005:4:160-70.

40. Frykberg RG, Veves A. Diabetic foot infections. Diabetes Metab Rev. 1996;12:255-70.

41. Pavicic T, Korting HC. Xerosis and callus formation as a key to the diabetic foot syndrome: dermatologic view of the problem and its management. J Dtsch Dermatol Ges. 2006;4:935-41.

42. Falanga V. Wound healing and its impairment in the diabetic foot. Lancet. 2005;366:1736-43.

43. Eaglstein WH, Callen JP. Dermatologic comorbidities of diabetes mellitus and related issues. Arch Dermatol. 2009:145:467-9. 
44. Ngo BT, Hayes KD, DiMiao DJ, Srinivasan SK, Huerter CJ, Rendell MS. Manifestations of cutaneous diabetic microangiopathy. Am J Clin Dermatol. 2005;6:225-37.

45. Gefen A. Plantar soft tissue loading under the medial metatarsals in the standing diabetic foot. Med Eng Phys. 2003;25:491-9.

46. Sakai S, Endo Y, Ozawa N, Sugawara T, Kusaka A, Sayo T, et al. Characteristics of the epidermis and stratum corneum of hairless mice with experimentally induced diabetes mellitus. J Invest Dermatol. 2003;120:79-85.

47. Yajima Y, Sueki H, Fujisawa R. Increased corneocyte surface area in the diabetic skin. Nihon Hifuka Gakkai Zasshi. 1991;101:129-34.

48. Moczar M, Allard R, Ouzilou J, Robert L, Bouissou H, Julian M, et al. Structural and biochemical alterations of human diabetic dermis studied by H-lysine incorporation and microscopy. Pathol Biol. 1976;24:329-36.

49. Hashmi F, Malone-Lee J, Hounsell E. Plantar skin in type II diabetes: an investigation of protein glycation and biomechanical properties of plantar epidermis. Eur J Dermatol. 2006;16:23-32.

50. Ganemo A, Virtanen M, Vahlquist A. Improved topical treatment of lamellar ichthyosis: a double-blind study of four different cream formulations. Br J Dermatol. 1999;141:1027-32.

51. Pierard GE, Seite S, Hermanns-Le T, Delvenne P, Scheen A, Pierard-Franchimont C. The skin landscape in diabetes mellitus. focus on dermocosmetic management. Clin Cosmet Investig Dermatol. 2013;6:127-35.

52. Schölermann A, Paschen B, Filbry A, Rippke F. Foot care with an 10\% urea emollient in diabetic and atopic patients: results of two clinical studies. J Eur Acad Dermatol Venereol. Poster Presentations at the 12th EADV congress Barcelona 2003.
53. Federici A, Federici G, Milani M. An urea, arginine and carnosine based cream (Ureadin Rx Db ISDIN) shows greater efficacy in the treatment of severe xerosis of the feet in Type 2 diabetic patients in comparison with glycerol-based emollient cream. A randomized, assessor-blinded, controlled trial. BMC Dermatol. 2012;12:16.

54. Garrigue E, Martini J, Cousty-Pech F, Rouquier A, Degouy A. Evaluation of the moisturizer Pedimed((R)) in the foot care of diabetic patients. Diabetes Metab. 2011;37:330-5.

55. Pham HT, Exelbert L, Segal-Owens AC, Veves A. A prospective, randomized, controlled double-blind study of a moisturizer for xerosis of the feet in patients with diabetes. Ostomy Wound Manag. 2002;48:30-6.

56. Papanas N, Papazoglou D, Papatheodorou K, Maltezos E. Evaluation of a new foam to increase skin hydration of the foot in type 2 diabetes: a pilot study. Int Wound J. 2011;8:297-300.

57. Seite S, Khemis A, Rougier A, Ortonne JP. Importance of treatment of skin xerosis in diabetes. J Eur Acad Dermatol Venereol. 2011;25:607-9.

58. Polaskova J, Pavlackova J, Vltavska P, Mokrejs P, Janis R. Moisturizing effect of topical cosmetic products applied to dry skin. J Cosmet Sci. 2013;64:329-40.

59. Nunes S, Mosca MM, Rosa VP, de Macedo GMC. Uncontrolled, open-label, single center clinical study to evaluate the perceived efficacy and acceptability of Hidrastar cream and lotion for feet in diabetic patients. Revista Brasileira de Medicina. 2015;72:195-9.

\section{Submit your next manuscript to BioMed Central and we will help you at every step:}

- We accept pre-submission inquiries

- Our selector tool helps you to find the most relevant journal

- We provide round the clock customer support

- Convenient online submission

- Thorough peer review

- Inclusion in PubMed and all major indexing services

- Maximum visibility for your research

Submit your manuscript at www.biomedcentral.com/submit
() Biomed Central 